\title{
On the Welding Behavior of a Galvannealed HSLA Steel
}

\author{
J. Nieto*, M.P. Guerrero-Mata*, R. Colás* and R. Garza**
}

*Universidad Autónoma de Nuevo Léon, Fac. de Ing. Mecánica y Eléctrica

Pedro de Alba S/N, Cd. Universitaria, San Nicolás de los Garza, N.L. 66450 MEXICO

${ }^{* *}$ Galvak, S.A. de C.V. Ave de la Juventud 340 Nte., San Nicolás, N.L. 66450 MEXICO

Different conditions were established to carry out a series of welding test on a HSLA steel with a chemical composition of $0.06 \mathrm{C}, 0.8 \mathrm{Mn}, 0.019 \mathrm{P}, 0.002 \mathrm{~S}, 0.002 \mathrm{Ti}, 0.02 \mathrm{Ni}, 0.02 \mathrm{Si}, 0.05 \mathrm{Cu}, 0.025$ $\mathrm{Nb}$ and $0.29 \mathrm{Al}$ (wt \%), microhardness was found to be $175.93 \mathrm{Hv}$. The average galvannealed coating was of $10.5 \mu \mathrm{m}$, and contained $12.99 \mathrm{Fe}, 0.4303 \mathrm{Al}, 0.018 \mathrm{Sb}$ and $0.0053 \mathrm{~Pb}$ (wt \%). Bending tests to 60 and $90^{\circ}$ were carried out on the galvanneled samples; weight losses of 0.141 and $0.0147 \mathrm{~g}$ resulted with these two conditions. The variables to consider in the welding tests were current (I), pulses $(\mathbf{P})$, hold time $(\mathbf{H t})$ and weld time $(\mathbf{W t})$. A force on the electrodes $(\mathbf{F})$ of $5782 \mathrm{~N}$, a squeeze time (St) of 99 cycles and a diameter of electrodes (d) of $7.9 \mathrm{~mm}$ were fixed throughout the experimentation, the electrodes were of a copper alloy with $1.79 \mathrm{Cr}$ and $0.78 \mathrm{Zr}$, higher contents of $\mathrm{Zr}$ are desirable to avoid the formation of brass and hence improve the lifetime and wore of the electrodes [1]. All the tests were conducted following an industrial procedure [2,3]. Most authors show results varying $\mathbf{F}, \mathbf{I}, \mathbf{H t}$ and $\mathbf{W t}$, however little information can be found on the variation of $\mathbf{P}$.

Tests were conducted varying I from 8 to $11 \mathrm{kA}$, Wt used was of either 16 and 18 cycles, Ht was either 5 or 30 , and $\mathbf{P}$ took values of 1 or 2 , yielding to a matrix of 40 experimental. The results show that Wt and Ht have the bigger effect on the size of the weld zone. When I ranges between 8 and 9 $\mathrm{kA}$, the nuggets from the welding zone suffer tearing, whereas from $9.5 \mathrm{kA}$ and above tearing starts from the sheet metal, rather than from the nugget, Fig 1. When $\mathbf{P}$ is equal to 1 , the welding behavior is more stable than with $\mathbf{P}$ equals to 2, Fig. 1. This figure also shows that the load resisted by the sheets is lower with $\mathbf{P}$ equals to 2 . This results agree with previously reported data [4]. It was found that the maximum current (up to expulsion) is larger for $\mathbf{P} 2$ than for $\mathbf{P} 1$, as the sheet metal is being cooled while in contact with the electrodes, therefore either more $\mathbf{W t}$, or $\mathbf{I}$ is needed to achieve the expulsion for $\mathbf{P} 2$. The minimum size of nugget can be produced with small values of $\mathbf{I}$ and short $\mathbf{W t}$, as for $\mathbf{P}$ 1, due to the absence of the intermediate cooling period between $\mathbf{P}$.

Fig. 2 shows a series of metallographies of the welded zones when either one or two pulses are used (P equals to 1 or 2 ) and the current, $\mathbf{I}$, is set either 8 or $11 \mathrm{kA}$, which represent the limits for welding, see Fig. 1. It can be seen that the penetration due to welding increases with the increment of current, and that the heat affected zone, is bigger in the material that had two pulses (P 2), as result of the time that the heat has to diffuse into the material. The results found in this work indicate that the amount of pulses used to weld the sheet metal affects the quality of the weld, but more than one pulse is sometimes the only way to weld sheets that have a thick coating, therefore, more efforts have to be conducted in this area. It is also recommended for further studies to take into account the coating roughness of the steel sheets, as well as that of the electrodes, as has been pointed out in previous research [5]. 
References

[1] F. Lu and C.L. White, Resistance Spot Welding Electrode Wear On Galvannealed Steels, Department Of Metallurgical And Materials Engineering, Michigan Technological University, Sep. 1997.

[2] Chrysler Coorporation Process Standard No. PS-9471.

[3] Resistance Welding Manual, Resistance Welder Manufacturers' Association, Philadelphia, USA, PA. 19103, 4th ed, 1999. pp. 1-1, 1-2.

[4] Fugetechnik, Schweisstechnik, Technical University, Berlin, Germany and Departament Of Mechanical Engineering, Indian Institute of Technology, Kharagpur, India, An Experimental Study Of Resistance Spot Welding In $1 \mathrm{~mm}$ Thick Sheet Of Low Carbon Steel, October 10, 1995.

[5] J. G. Kaiser et al, The Effect Of Electrical Resistance On Nugget Formation During Spot Welding, Supplement to the Welding Journal, 6 (1982).
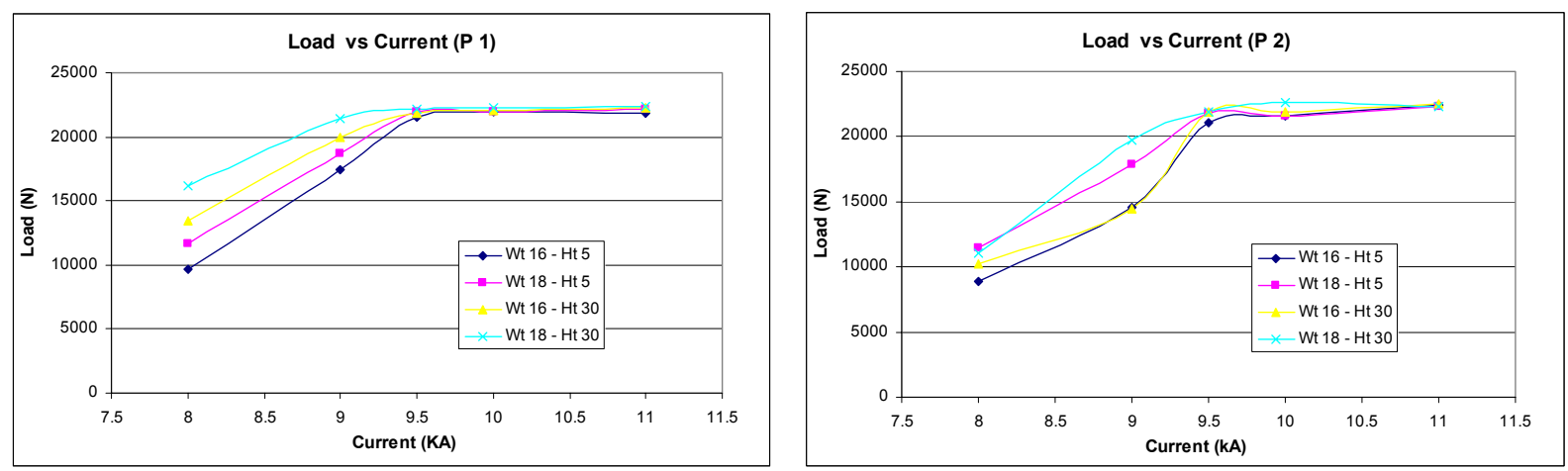

Fig. 1 Results from tension testing, a)P 1, b)P 2, at different values of $\mathbf{I}, \mathbf{W t}$ and $\mathbf{H t}$.
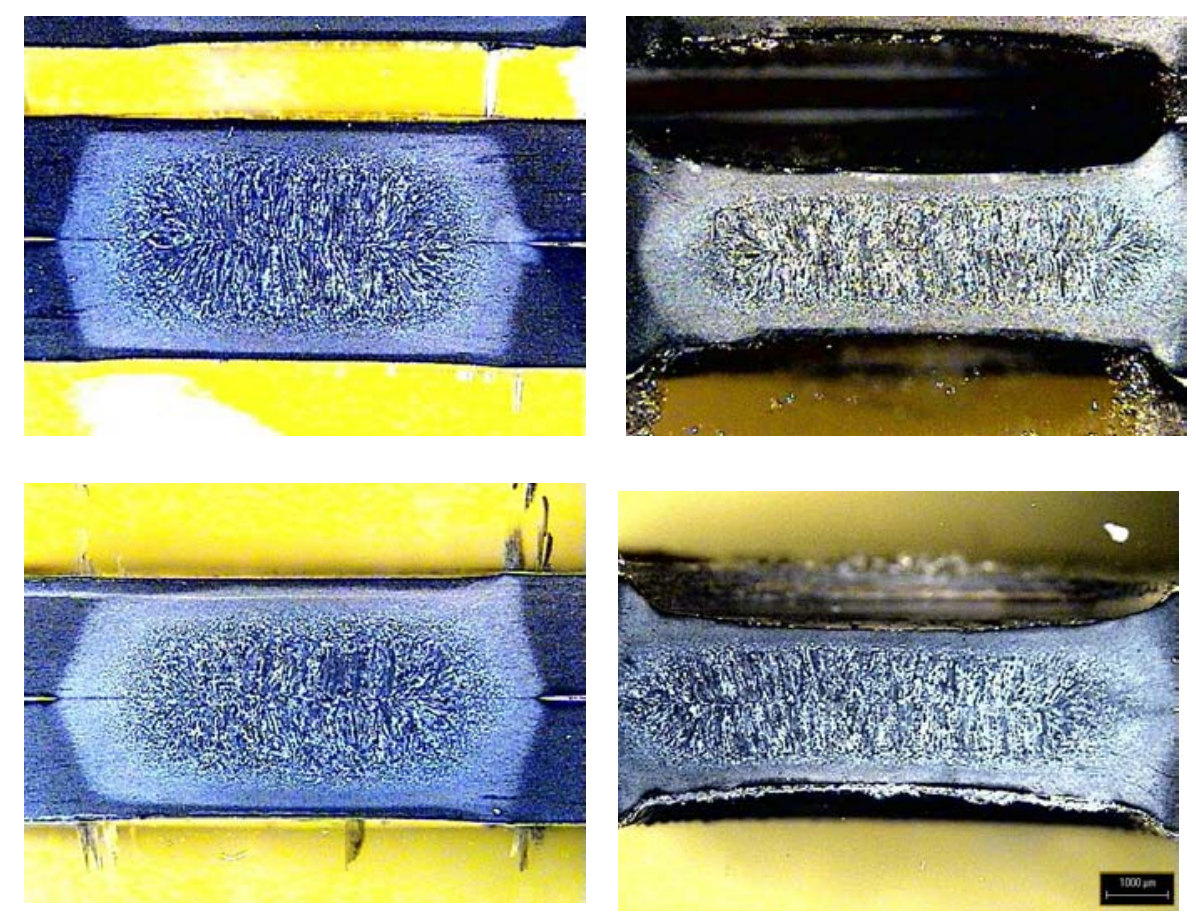

Fig. 2 a) P 1 Wt 16 c, Ht 30 c, I $8 \mathrm{kA} \mathrm{b)P} 1$ Wt 16 c, Ht 30 c, I $11 \mathrm{kA} \mathrm{c)P} 2$ Wt 16c, Ht 30c, I 8 kA) d) P 2 Wt 16c, Ht 30c, I 11kA. 